\title{
NATIONAL TAIWAN UNIVERSITY RADIOCARBON MEASUREMENTS I
}

\author{
YUIN-CHI HSU, CHIA-YI HUANG, and SHIH-CHONG LU* \\ Department of Physics, National Taiwan University, \\ Taipei, Taiwan, China
}

Natural $\mathrm{C}^{14}$ measurements have been performed at the Dept. of Physics, National Taiwan University since 1965, using a cylindrical proportional counter of $1000 \mathrm{ml}$ (Hsu et al., 1965). The proportional counter is operated with $\mathrm{CO}_{2}$ as the filling gas at a pressure of $1216 \mathrm{~mm} \mathrm{Hg}$ at room temperature of $20^{\circ} \mathrm{C}$. Working voltage is $4.7 \mathrm{Kv}$, with a plateau length of more than $700 \mathrm{v}$ and a plateau slope of ca. $1 \%$ per $100 \mathrm{v}$. Background is reduced to 5.1 counts/min and the counting rate of the NBS oxalic acid standard is 9.4 counts/min at the normal counting pressure of $1216 \mathrm{~mm} \mathrm{Hg}$.

The counter, which is shielded by iron plates of $25 \mathrm{~cm}$ thickness and by anti-coincidence with a multianode propane-flow proportional counter of Houtermans' type (Houtermans and Oeschger, 1955), is connected by copper tubing to a pumping system (rotary and diffusion pump with liquid air trap). The vacuum inside the counter is better than $10^{-5}$ $\mathrm{mm} \mathrm{Hg}$.

Samples are first examined under a binocular to pick up as many rootlets as possible and to remove foreign matters. They are then treated with $2 \% \mathrm{NaOH}$ and $2 \% \mathrm{HCl}$. After being rinsed with distilled water and dried, they are burnt in a stream of oxygen. The released $\mathrm{CO}_{2}$ is passed through hot $\mathrm{CuO}$ and absorbed in aqueous ammonia. Then it is precipitated as calcium carbonate after calcium chloride solution is added. After washing with hot distilled water and drying, the pure calcium carbonate is placed in a quartz tube which is kept at a temperature of $400^{\circ} \mathrm{C}$ and evacuated for more than five hours. The carbon dioxide is liberated by raising the temperature to $800^{\circ} \mathrm{C}$ and passed through dryice trap, frozen out by a serial of liquid air traps, purified by pumping off gaseous impurities between displacement from one trap to another in a solid state with a diffusion pump and finally evaporated into the counter.

Every sample is counted for at least 48 hours. Background determinations have been based on $\mathrm{CO}_{2}$ obtained from marble. All ages are calculated using as "living" standard 0.95 of the activity measured on NBS oxalic acid and $5570 \mathrm{yr}$ for the half-life of $\mathrm{C}^{14}, 1950$ being the reference year. Errors quoted include the standard deviations of the count rates for the unknown sample, the contemporary standard, and the background.

In this article, results obtained for geologic, archaeologic, and geophysical samples are described. The description of each sample is based on information provided by the person submitting the sample to the laboratory.

* Observation Division, Taiwan Provincial Weather Bureau, Taipei, Taiwan, China. 


\section{ACKNOWLEDGMENTS}

Thanks are extended to S. Y. Lin, M. C. Chou, and Y. C. Hsu for assistance in the preparation and measurement of samples.

\section{SAMPLE DESCRIPTIONS}

\section{GEOLOGIC SAMPLES}

\section{A. China}

\section{NTU-68. Chinmun Island}

Peat from $+30 \mathrm{~m}$, at $0.5 \mathrm{~m}$ depth, in farm of Houlong, Chinmun I., Fukien prov., China (24 $24^{\prime} \mathrm{N}$ Lat, $116^{\circ} 25^{\prime} \mathrm{E}$ Long). Coll. 1958 by Fu-Yin Lin and subm. 1969 by Pei-Yuan Chen, Dept. of Geol., Natl. Taiwan Univ. Comment (P.Y.C.): sample is from peat deposit of Quaternary age from Chinmun I. (Lin, 1958). According to present data, deposit should be from middle Holocene time.

\section{B. Malaysia}

\section{NTU-73. Malaysia}

Driftwood found at ca. $+100 \mathrm{~m}, 20 \mathrm{~m}$ deep, at Ipoh, Perak, Malaysia (04 $34^{\prime} \mathrm{N}$ Lat, $101^{\circ} 06^{\prime}$ E Long). Coll. 1968 and subm. 1969 by Y. Wang, Dept. of Geol., Natl. Taiwan Univ. Comment (Y.W.): date is appropriate provided that this part of Malay Peninsula has been subjected to longterm erosion (Ingham and Bradford, 1960) and recent rate of deposition has been very slow.

\section{ARCHAEOLOGIC SAMPLES}

\section{China}

\section{Hsi-hsin-chuang-tze series}

Shell (corbicula subsulcata) found from Early Iron age shell mound at Hsi-hsin-chuang-tze, Taipei, Taiwan, China $\left(25^{\circ} 04^{\prime} \mathrm{N}\right.$ Lat, $121^{\circ} 31^{\prime}$ E Long), at $+5 \mathrm{~m}$. Coll. 1967 and subm. 1968 by W. H. Sung, Dept. of Archaeol. and Anthropol., Natl. Taiwan Univ.

\section{NTU-52. Hsi-hsin-chuang-tze 1}

Ca. $1.1 \mathrm{~m}$ depth.

\section{NTU-53. Hsi-hsin-chuang-tze 2}

Ca. $0.7 \mathrm{~m}$ depth.

\section{NTU-54. Hsi-hsin-chuang-tze 3}

Ca. $0.3 \mathrm{~m}$ depth. Comment (W.H.S.): dates seem to agree with estimates based on cultural materials which may compare in part with the Shih-san-hang site (Sung, 1965), $1444 \pm 204$ and $1145 \pm 206$ (NTU-7 and NTU-8, Hsu and Huang, 1965) and the Fan-tze-yuan site $1500 \pm$ 80; Y-1499 (Sung, 1965).

$$
\begin{aligned}
& 1940 \pm 190 \\
& \text { A.D. } 10 \\
& 2390 \pm 200 \\
& 440 \text { B.C. }
\end{aligned}
$$

$2010 \pm 200$

\section{B.C.}




\section{NTU-55. Chishivayan, Ch'i-lin}

$3060 \pm 280$

Charcoal from Megalithic site at Chishivayan, Ch'i-lin, Taitung, Taiwan (23 $06^{\prime} \mathrm{N}$ Lat, $121^{\circ} 21^{\prime} \mathrm{E}$ Long), at $+80 \mathrm{~m}, 0.8 \mathrm{~m}$ depth. Coll. and subm. 1968 by W. H. Sung. Comment (W.H.S.): date seems to agree with estimates based on cultural material.

General Comment (W.H.S.): NTU-52, NTU-53, NTU-54, and NTU-55 were all closely connected with floor level of megalithic feature at T1P4 pit (Sung, 1969).

\section{Tung-chiao series}

Charcoal fragments in sandy soil, at $+300 \mathrm{~m}$, at Tung-chiao, Chi-chi, Nan-t'ou Hsien, Taiwan (23० $45^{\prime} \mathrm{N}$ Lat, $120^{\circ} 47^{\prime} \mathrm{E}$ Long). Coll. and subm. 1968 by Judith M. Treistman, Dept. of Archaeol. and Anthropol., Natl. Taiwan Univ.

\section{NTU-56. Tung-chiao 1}

$$
1630 \pm 160
$$

From ca. $0.68 \mathrm{~m}$ depth. Comment (J.M.T.): appears younger than expected. Cultural materials may compare in part with Yin P'u site (Huang, 1968), which has $\mathrm{C}^{14}$ dates ranging between $2970 \pm 80$ (Y-1630, Sung, 1965) to $2250 \pm 60$; Y-1632 (Sung, 1965).

\section{NTU-57. Tung-chiao 2}

$3840 \pm 380$

From ca. $0.5 \mathrm{~m}$ depth. Comment (J.M.T.): age seems to agree with estimates based on cultural material.

\section{Fukuotun series, Chinmun Island}

Shell mound consists of abundant shells, including some blackish and brownish pottery fragments, with or without sculptured patterns. Coll. 1968 by C. C. Lin, Dept. of Geol., Natl. Taiwan Univ., at Chinmun I., Fuchien prov., China (24 $40^{\prime} \mathrm{N}$ Lat, $\left.118^{\circ} 30^{\prime} \mathrm{E} \mathrm{Long}\right)$, at ca. $+40 \mathrm{~m}$. Comment (C.C.L.): thickness of shell mound is ca. $70 \mathrm{~cm}$ and the only archaeol. site ever found on the Island.

NTU-63. Fukuotun 1

$5460 \pm 320$

Shell samples from 10 to $20 \mathrm{~cm}$ depth.

NTU-64. Fukuotun 2

3510 B.C.

Shells from 40 to $50 \mathrm{~cm}$ depth.

NTU-65. Fukuotun 3

$5800 \pm 340$ 3850 B.c.

Shells from 70 to $80 \mathrm{~cm}$ depth.

$6310 \pm 370$

4360 B.c.

\section{Chang-pin series}

Charcoal from LHII (Sung, 1969) Cave, Chang-pin, Taitung, Taiwan $\left(23^{\circ} 24^{\prime} \mathrm{N}\right.$ Lat, $121^{\circ} 25^{\prime} \mathrm{E}$ Long), at $+40 \mathrm{~m}$. Coll. and subm. 1969 by W. H. Sung. 
$5240 \pm 260$

NTU-69. Chang-pin 1

3290 B.C.

From ca. $1.22 \mathrm{~m}$ depth from preceramic cultural layer at T4P2NE pit.

NTU-70. Chang-pin 2

$5340 \pm 260$

From ca. $1.03 \mathrm{~m}$ depth from preceramic cultural layer at T3P1S pit.

\section{NTU-71. Chang-pin 3}

$4970 \pm 250$

3020 B.C.

From ca. 0.75 to $0.85 \mathrm{~m}$ depth from preceramic cultural layer of T3P2S pit. Comment (W.H.S.): NTU-69, NTU-70, and NTU-71 samples appear younger than expected. Cultural materials may compare in part with those from Tabon Cave, Palawan, Philippines, which have $\mathrm{C}^{14}$ dates ranging between 7,000 to $30,000 \mathrm{yr}$ ago (Fox, n.d. and 1968).

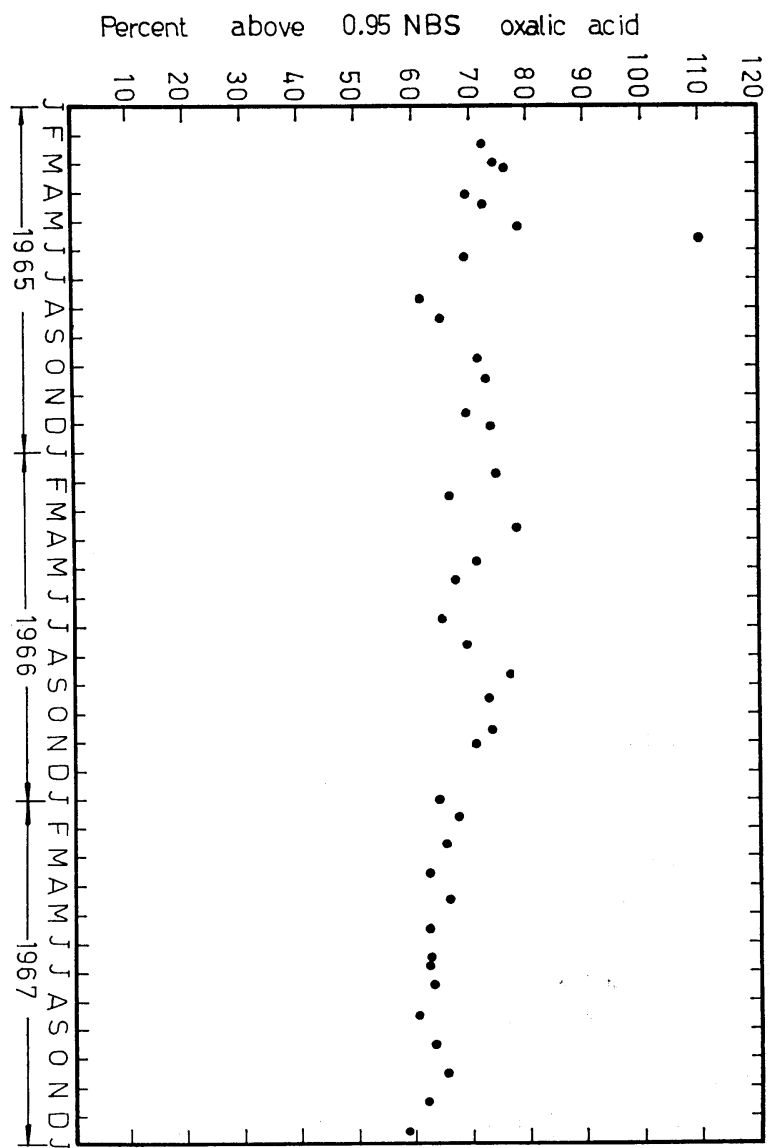

Fig. 1. $\mathrm{C}^{14}$ enrichment over NBS standard of atmospheric $\mathrm{CO}_{2}$ during 1965 to 1967 at Taipei, Taiwan $\left(25^{\circ} 02^{\prime} \mathrm{N}\right.$ Lat, $121^{\circ} 31^{\prime} \mathrm{E}$ Long). 
General Comment (W.H.S.): younger dates of samples might be caused by inherent contamination.

III. GEOPHYSICAL SAMPLES

\section{$C^{14}$ in Atmospheric Carbon Dioxide}

\section{Atmospheric Radiocarbon Activity series, Taipei}

$\mathrm{C}^{14}$ content in ground level atmospheric $\mathrm{CO}_{2}$ is monitored monthly at Taipei, Taiwan $\left(25^{\circ} 02^{\prime} \mathrm{N}\right.$ Lat, $121^{\circ} 31^{\prime} \mathrm{E}$ Long).

The following list contains exposure time of $\mathrm{NaOH}$ solutions to air and per cent increase of $\delta \mathrm{C}^{14}$ above $95 \%$ NBS oxalic acid. Data are graphed in Fig. 1. The statistical error is less than $1 \%$. Comment (authors): the unusually high value of NTU-80 for collection period 19 May-25 May 1965 may be due to the nuclear test in the mainland of China on 13 May 1965.

\begin{tabular}{c} 
Sample no. \\
\hline NTU-74 \\
NTU-75 \\
NTU-76 \\
NTU-77 \\
NTU-78 \\
NTU-79 \\
NTU-80 \\
NTU-81 \\
NTU-82 \\
NTU-83 \\
NTU-84 \\
NTU-85 \\
NTU-86 \\
NTU-87 \\
NTU-88 \\
NTU-89 \\
NTU-90 \\
NTU-91 \\
NTU-92 \\
NTU-93 \\
NTU-94 \\
NTU-95 \\
NTU-96 \\
NTU-97 \\
NTU-98 \\
NTU-99 \\
NTU-100 \\
NTU-101 \\
NTU-102 \\
NTU-103
\end{tabular}

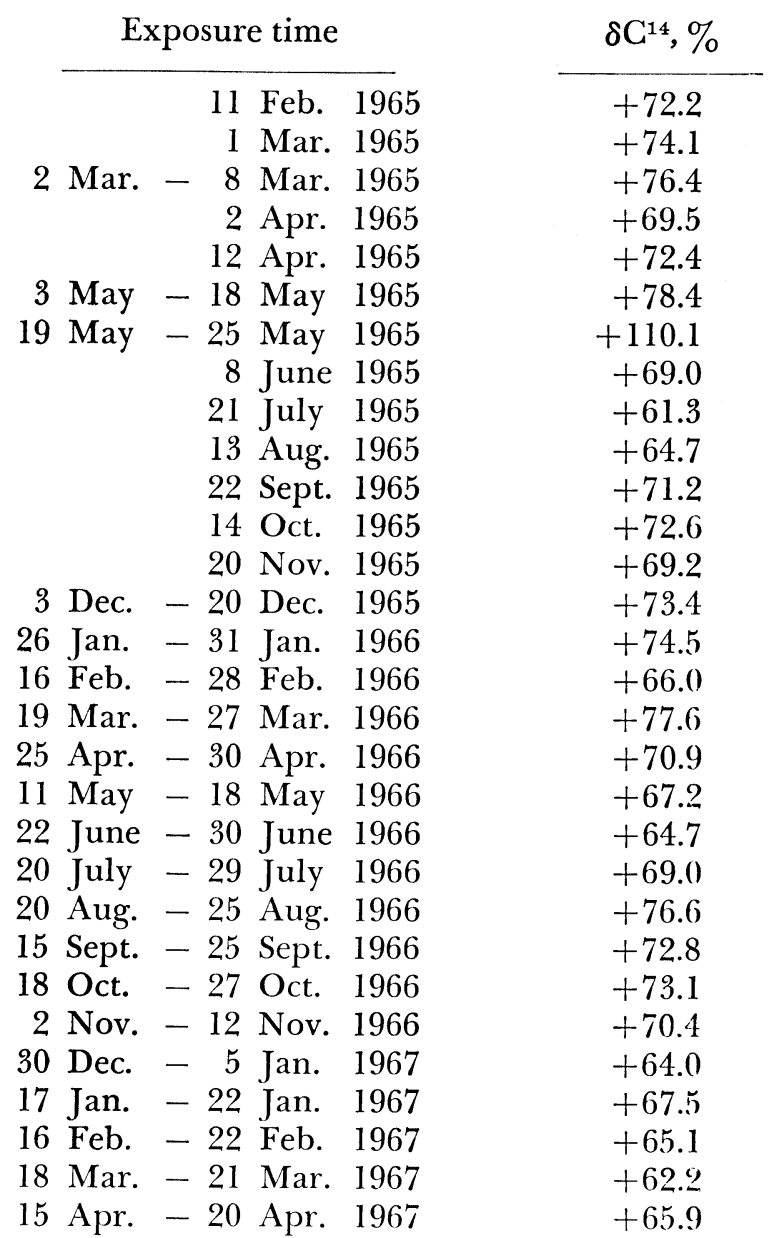


Sample no.

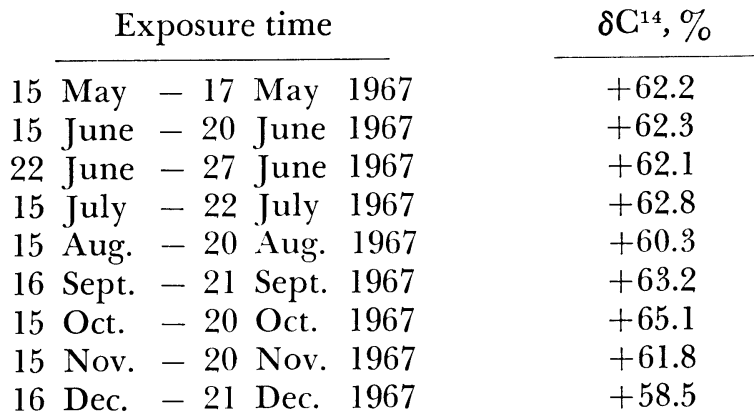

\section{REFERENCES}

Fox, R. B., n.d., Ancient man in Palawan: a progress rept. of current excavations. Natl. Mus. p. 1-18.

1968, The palaeolithic in the Philippines: Abs. of sectional meetings VIIIth Internatl. Cong. of Anthropol. and Ethnol. Sciences, Tokyo, p. 230.

Houtermans, F. G. and Oeschger, H., 1955, Proportionalzählrohr zur Messung schwacher Aktivitäten weicher $\beta$-strahlung: Helvetica Phys. Acta, v. 28, p. 464-466.

Hsu, Y. C. et al., 1965, Low background counter for carbon-14 dating: Chinese Jour. Physics, v. 3, p. 1-9.

Hisu, Y. C. and Huang, C. Y., 1965, Carbon-14 dating I: Chinese Jour. Physics, v. 3, p. $120-122$.

Huang, S. C., 1968, Archaeological fieldworks in Taiwan during the past two vears: supplementary proc. of the seminar on Taiwan studies occasional papers of the Dept. of Archaeol. and Anthropol. Natl. Taiwan Univ., no. 5, p. 11-13.

Ingham, E. T. and Bradford, E. F., 1960, The geology and mineral resources of the Kinta Valley, Perak: Malaya, Geol. Surv., Mem. 9, p. 347.

I.in, F. Y., 1958, A note on the peat deposit from Houlong farm, Chinmun Island: Ministry of Economic Affairs Rept.

Sung, W. H., 1965, Chronology of the Prehistoric cultural sequences of Western Formosa: Taiwan Wen Shien Rept. of Historic-Geog. Studies of Taiwan, v. 16, p. $144-155$.

1969, Changpinian: a newly discovered Preceramic culture from the Agglomerate Caves on the east coast of Taiwan: Newsletter of Chinese Ethnol., no. 9. 